\title{
Short Communication: Spermicidal properties of Durio zibethinus in the Mandiangin Forests, South Kalimantan, Indonesia
}

\author{
ANNI NURLIANI ${ }^{1, \boldsymbol{v}}$, NANI KARTINAH ${ }^{2}$ \\ ${ }^{1}$ Department of Biology, Faculty of Mathematics and Natural Sciences, Universitas Lambung Mangkurat. J1. A. Yani Km. 35.8 Banjarbaru 70714, South \\ Kalimantan, Indonesia. Tel./Fax.+62-511-4773868, `email: nurliani_anni@yahoo.co.id \\ ${ }^{2}$ Department Pharmacy, Faculty of Mathematics and Natural Sciences, Universitas Lambung Mangkurat. J1. A. Yani Km. 35.8 Banjarbaru 70714, South \\ Kalimantan, Indonesia. Tel./Fax. +62-511-4773868
}

Manuscript received: 10 May 2016. Revision accepted: 11 February 2017.

\begin{abstract}
Nurliani A, Kartinah N. 2017. Short Communication: Spermicidal properties of Durio zibethinus in the Mandiangin Forests, South Kalimantan, Indonesia. Biofarmasi J Nat Prod Biochem 15: 26-28. Side effects caused by a condom with synthetic spermicide encourage researchers to find alternative spermicides from plants with fewer side effects. The bark of durian extract is a potential candidate for herbal spermicide because it could decrease the percentage of human spermatozoa quality in vitro at the concentrations of $2 \%$. This study evaluated its spermicidal activity in vitro on human spermatozoa's motility, movement velocity, viability, and morphology. The gel formulation with $2 \%$ of the bark of durian extract was developed using hydroxypropyl methylcellulose as a gelling agent with 3 different concentrations, namely, 1.5, 2, and $2.5 \%$. Evaluation of gel preparations, including physical appearance, viscosity, spreadability, and $\mathrm{pH}$, was done to obtain the best formula. Based on the evaluation, the best performance of gel was achieved by adding $2 \%$ of HPMC. Furthermore, the spermicidal activity of the gel with the bark of durian extract was tested and compared to the bark of durian extract without gel, gel without bark of durian extract, and the fresh sperm as control. Formulation of gel with the bark of durian extract significantly decreased all parameters of spermatozoa quality. Thus, a formula containing $2 \%$ of the bark of durian extract with HPMC $2 \%$ possesses appreciable spermicidal potential.
\end{abstract}

Keywords: Durian, gel, human sperm, Kalimantan, spermicide

\section{INTRODUCTION}

Since the 19th century, the condom has become one of the most popular contraceptive methods globally and used for at least 400 years. To increase its effectiveness, some condoms are lubricated with spermicide chemicals such as nonoxynol-9 (Kestelman and Trussell 1991). However, recent studies indicate that nonoxynol-9 may cause irritation and increase the risk of HIV (Asif 2013).

To resolve this problem, efforts to develop safe and effective contraceptives must be made. Herbal contraceptives are in popular demand because they have fewer side effects. The previous investigation revealed that the barks of durian extract have spermicidal activity on human spermatozoa in vitro. The extract from the bark of durian could decrease the percentage of quality of human spermatozoa in vitro at the concentrations of $2 \%$ (Nurliani and Santoso 2010).

Gels are often used pharmaceutically as lubricants and as carriers for spermicidal agents (Esposito et al. 1996). Therefore, this study was designed to formulate and evaluate spermicidal gel containing bark of durian extract for application in humans as an herbal spermicide in condoms.

\section{MATERIALS AND METHODS}

\section{Plant materials}

The bark of durian was collected from the forest region of Mandiangin, South Kalimantan, Indonesia.

\section{Chemicals}

Ethanol (Merck Ltd), Hydroxypropyl Methyl Cellulose (HPMC), propylene glycol, glycerin, methylparaben, propylparaben, Hank's Balanced Salt Solution (HBSS) Gibco®, eosin-Y, nigrosin, Giemsa, and methanol.

\section{Sample}

Semen samples were donated by 6 healthy fertile men (25-30 years old). Semen samples were collected by masturbation in sterile glass cups after at least 3 days of sexual abstinence.

\section{Preparation of bark powder}

The bark was dried under shade and then powdered coarsely with a mechanical grinder. The powder was passed through sieve No. 40 and stored in an airtight container for further use.

\section{Preparation of extracts}

Every $50 \mathrm{~g}$ of dried powder of bark was subjected to soxhlet apparatus. It was exhaustively extracted with 250 
$\mathrm{mL}$ of ethanol solvent in a soxhlet apparatus. The temperature was maintained at $\left(60-70^{\circ} \mathrm{C}\right)$. The solvents were removed by distillation under reduced pressure, and the resulting semisolid mass was vacuum-dried using a rotary flash evaporator to obtain the extract.

\section{Preparation of gel formulation}

The spermicidal gel was formed from a mixture of HPMC, propylene glycol, glycerin, methylparaben, propylparaben, and $2 \%$ of the bark of durian extract. There are three formulas with various concentration of HPMC, i.e., $1.5 \%(\mathrm{~F} 1)$; $2 \%(\mathrm{~F} 2)$; and $2.5 \%(\mathrm{~F} 3)$. HPMC was dispersed in distilled water with continuous stirring. Distilled water was taken, and the required quantity of methylparaben and propylparaben was dissolved by heating in a water bath. The solution was cooled, added glycerin, and mixed with the first solution. Further required quantity of durian bark extract was mixed with the above mixture, and the volume was made up to $100 \mathrm{~mL}$ by adding the remaining distilled water. Finally, full ingredients were mixed properly into the HPMC gel with continuous stirring, and propylene glycol was added dropwise to the formulation for consistency (Sudipta et al., 2011).

\section{Evaluation of gel formulation}

Physical evaluation. The color and odor of the prepared gels were checked.

Measurement of $\mathrm{pH}$. The $\mathrm{pH}$ of the gel was measured using a pH meter.

Spreadability. The spreadability of the gel formulations was determined by measuring the spreading diameter of $1 \mathrm{~g}$ of gel between two horizontal plates $(20 \mathrm{~cm} \times 20 \mathrm{~cm})$ after one minute. The standard weight applied on the upper plate was $50 \mathrm{~g}$.

Viscosity. The viscosity of the gel was measured using a Brookfield viscometer with the spindle. The reading was taken at $1000 \mathrm{rpm}$ using spindle no. 4.

\section{Sample preparation}

Semen samples were donated by 6 healthy fertile men (25-30 years old). Semen samples were collected by masturbation in sterile glass cups after at least 3 days of sexual abstinence. Spermatozoa free of seminal plasma were obtained by centrifugation at $1,900 \mathrm{rpm}$ for 20 minutes and adjusted in Hank's Balanced Salt Solution (HBSS) media. Then it was made into a pellet by microcentrifugation at $1000 \mathrm{rpm}$ for 10 minutes (Purwaningsih 2000).

\section{Experimental procedure}

Semen samples were added to the gel of bark extract preparation and then assessed immediately for these parameters below.

Sperm motility. A drop of the evenly mixed sample was immediately placed on a clean and dry glass slide covered with a coverslip. This slide was then examined under the binocular microscope (Olympus, Japan) at magnifications of $\mathrm{x} 10$ and $\mathrm{x} 40$. At least five fields were rapidly examined, and 100 spermatozoa were counted (Hyacinth et al., 2012).
Movement velocity of sperm. The velocity of spermatozoa was measured by calculating the time (seconds) needed by motile spermatozoa to reach 1 box microhaemocytometer. The velocity of spermatozoa is defined with a micrometer per the second unit.

Sperm viability. One drop of above-treated sperm mixed with 2 drops of $1 \%$ EosinY. After $30 \mathrm{~s}, 3$ drops of $10 \%$ Nigrosin solution were added. A drop of treated sperm-Eosin-Nigrosin mixture is placed on a clear microscope slide, allowed to dry, and observed under a microscope. Live spermatozoa had whiteheads, and dead spermatozoa had heads stained red or dark pink. A total of 100 spermatozoa were evaluated manually on each slide at right-field optics at $400 \mathrm{x}$ magnification (Eliasson 1977).

Sperm morphology. The sperm morphology of treated sperm was studied under the microscope using the EosinY and Nigrosin staining methods described above. A drop of sperm-eosiny-nigrosin mixture treated with gel of bark extract was examined separately at $400 \mathrm{X}$ under a phasecontrast microscope to record any change in the morphology of the sperm (Jayendran et al. 1994).

\section{Statistical analysis}

Data were analyzed with the SPSS system and presented as mean \pm standard deviation (SD). Statistical significance was evaluated with a Nonparametric test (Kruskal-Wallis), and the difference was considered statistically significant at $\mathrm{P}<0.05$.

\section{RESULTS AND DISCUSSION}

The result of the physical evaluation of gel formulation can be seen in Table 1. The physical evaluation showed that all the formulations show similar organoleptic properties with brownish coloration due to the plant extract and a specific smell. The $\mathrm{pH}$ of the gel formulations was in the range of 4.61-4.96, which lies in the normal $\mathrm{pH}$ range of the skin and would not produce any skin irritation. The ideal $\mathrm{pH}$ value for the gel is 4.5-7 (Wasiaatmadja 1997). The spreadability of gel was evaluated to test the ease of applicability of gels on skin. The spreadability of formulated gels was decreased as the concentration of polymer increased. Spreadabilities of formulated gels (F1, F2, and F3) were 5.26, 5.00, and $7.93 \mathrm{~cm}$, respectively. The ideal value of spreadability for the gel is $5-7 \mathrm{~cm}$ (Garg et al. 2002). Hence, the spreadability of the F2 and F3 formulation was better than F1formulation. Viscosity is an important parameter for characterizing the gels, affecting the spreadability. The viscosity of gels increased with the increase in polymer content, which may be due to the increase in the formation of the three-dimensional crosslinking gel structure, as expected. The ideal viscosity value for the gel is 2,000-50,000 Cps (SNI 1996). By comparing the viscosity values, the F3 formulation has an over the viscosity value. The viscosity of the $\mathrm{F} 1$ and $\mathrm{F} 2$ formulations were more ideal than the F3 formulation. According to the evaluation result, the $\mathrm{F} 2$ formulation with a $2 \%$ proportion of HPMC resulted in the best gel formulation. 
Tabel 1. Evaluation of gel formulation

\begin{tabular}{llccc}
\hline Formulations & Color and odor & pH & Spreadability (cm) & Viscosity (Cps) \\
\hline F1 & Brownish and specific smell & 4.95 & 5.26 & 15000 \\
F2 & Brownish and specific smell & 4.63 & 5.00 & 30000 \\
F3 & Brownish and specific smell & 4.67 & 7.93 & 82000 \\
\hline
\end{tabular}

Table 2. Quality of human sperm following incubation with gel of durian bark extract

\begin{tabular}{lcccc}
\hline Treatment & $\begin{array}{c}\text { Motility } \\
(\boldsymbol{\%})\end{array}$ & $\begin{array}{c}\text { Movement } \\
\text { Velocity }(\boldsymbol{\mu m} / \mathbf{s})\end{array}$ & $\begin{array}{c}\text { Viability } \\
(\boldsymbol{\%})\end{array}$ & $\begin{array}{c}\text { Normal } \\
\text { Morphology }(\boldsymbol{\%})\end{array}$ \\
\hline Control (Fresh sperm + HBSS) & $80.00 \pm 8.944 \mathrm{a}$ & $0.64 \pm 0.476^{\mathrm{a}}$ & $79.67 \pm 4.179 \mathrm{a}$ & $84.17 \pm 6.242^{\mathrm{a}}$ \\
Gel without extract & $5.50 \pm 3.619 \mathrm{~b}$ & $0.54 \pm 0.406^{\mathrm{a}}$ & $73.67 \pm 8.756 \mathrm{a}$ & $89.83 \pm 2.787^{\mathrm{a}}$ \\
Bark of durian extract at the concentration of $2 \%$ & $3.00 \pm 1.4142 \mathrm{~b}$ & $0.12 \pm 1.469^{\mathrm{b}}$ & $4.33 \pm 4.033 \mathrm{~b}$ & $23.17 \pm 6.274^{\mathrm{b}}$ \\
Gel containing bark of durian extract & $0.00 \pm 0.000 \mathrm{c}$ & $0.00 \pm 0.000^{\mathrm{c}}$ & $0.00 \pm 0.000 \mathrm{c}$ & $20.17 \pm 7.413^{\mathrm{b}}$ \\
\hline
\end{tabular}

The assessment of spermicidal activity from the gel of bark durian extract can be seen in Table 2. The present study evaluated the spermicidal properties of the gel with the bark of durian extract. It revealed a reduction $(\mathrm{P}<0.05)$ in the percentage of motility, viability, normal morphology, and movement velocity of human spermatozoa. The results indicate that formulation of gel with the bark of durian extract decreased the percentage of motility, movement velocity, and viability of human spermatozoa significantly up to $0 \%$ and normal morphology of spermatozoa up to $20.17 \%$. The percentage of motility, movement of velocity, viability, and normal morphology of human spermatozoa in gel preparation with the bark of durian extract have significant differences with the bark of durian extract without gel, gel without extract, and with control (Table 2). Gel with the bark of durian extract has better spermicidal activity than the bark of durian extract without gel.

Phytochemistry screening of the extract of durian barks revealed the presence of alkaloids, flavonoids, tannins, steroids, triterpenoids, and saponins. A large number of plants for spermicidal have been screened, and a majority of plant-derived spermicides reported are triterpene saponins of several structural types, flavonoids, and phenol compounds (Farnsworth and Waller 1982). The saponins of several plants have been reported to produce instant immobilization of human spermatozoa within 20 seconds (Primorac et al. 1985). Most plant-derived spermicides, which caused inhibition of the sperm-specific enzymes acrosin and hyaluronidase, were confirmed to contain flavonoids. It is believed that flavonoids and their derivatives, flavanones, and flavonols, contain hyaluronidase inhibitory activity (Farnsworth and Waller 1982). The results indicate that the gel with the bark of durian extract possesses strong spermicidal activity in vitro. However, the mechanism of action from active components of the bark of durian extract as spermicidal agents should be further evaluated.

Based on the spermicidal activity result, the formulation of gel containing a $2 \%$ bark of durian extract possesses appreciable spermicidal potential, which may be explored as an effective constituent of male contraceptives.

\section{ACKNOWLEDGEMENTS}

The author wishes to thank the Directorate General of Higher Education of Indonesia for providing a grant under Research Contract No. 056/UN8.2/PL/2015.

\section{REFERENCES}

Asif M. 2013. A review on spermicidal activities of Azadirachta indica. J Pharm Phytol 1 (5): 61-79.

Eliasson R. 1977. Supravital staining of human spermatozoa. Fert Steril 28: 1257.

Esposito E, Carotta V, Scabbita A. 1996. Cutaneous and Transdermal Delivery: Processes and systems of Delivery. In: Baker GS, Rhodes C (eds.). Modern Pharmaceutics. Marcel Dekker Inc., USA.

Farnsworth NR, Waller DP. 1982. Current status of plant products reported to inhibit sperm. In: Zatuchni GI (ed.). Research Frontiers in Fertility Regulation, Northwestern University, Evanston.

Garg A, Aggarwal D, Garg S, Sigla AK. 2002. Spreading of Semisolid Formulation. Pharmaceutical Technology, USA.

Hyacinth AA, Terzungwe A, Owoicho OD, Mathias AA. 2012. Evaluation of spermicidal property of aqueous ethanolic extract of Lawsonia inermis Linn. leaves. Ann Biol Res. 3 (8): 3846-3848.

Jayendran RS, Vander VEN, Perez-pelaez M, Crabo BG, Zaneveld LJD. 1994. Development of an assay to assess the functional integrity of the human sperm membrane and its relationship to other semen characteristics. J Reprod Fert 70: 219-228.

Kestelman P, Trussell J. 1991. Efficacy of the simultaneous use of condoms and spermicides. Fam Plann Perspect 23 (5): 226-227, 232.

Nurliani A, Santoso HB. 2010. Spermaticide effect from bark of durian extract (Durio zibethinus Murr.) to motility and velocity movement of human spermatozoa quality by in vitro. J Sci Appl Chem 4 (1): 72-78.

Primorac M, Sekulovic D, Antonic S. 1985. In vitro determination of the spermicidal activity of plant saponins. Pharmazie 40: 585

Purwaningsih E. 2000. Spermaticidal effect of Hibiscus rosa-sinensis L. leaves extract to quality of human spermatozoa In vitro. J Med YARSI 8 (3): 13-18.

SNI. 1996. SNI 16-4399-1996 Sediaan Tabir Surya. Council of Dewan Standardisasi Nasional, Jakarta. [Indonesian]

Sudipta D, Pallab KH, Goutam P. 2011. Formulation and evaluation of herbal gel containing Clerodendron infortunatum leaves extract. Int $\mathrm{J}$ Pharm Tech Res 3 (1): 140-143.

Wasiaatmadja SM. 1997. Penuntun Ilmu Kosmetik Medik. UI-Press, Jakarta. [Indonesian] 